\title{
Phycoremediation of arsenic by Chlorella sp. CB4
}

\author{
M.O. Alam, S. Chakraborty \& T. Bhattacharya \\ Department of Civil and Environmental Engineering, Birla Institute of Technology, Mesra, India
}

\begin{abstract}
At the dawn of 21st century, phycoremediation has received significant attention as a feasible technique for arsenic removal from contaminated water. Here a study was attempted to assess the potential of microalgae Chlorella sp. CB4 to remove $\mathrm{As}(\mathrm{III})$ and $\mathrm{As}(\mathrm{V})$ from aqueous phase in optimized conditions. Removal efficiency achieved for $\mathrm{As}(\mathrm{V})$ was $87 \%$ and for $\mathrm{As}(\mathrm{III})$ was $86 \%$ in optimized condition. In groundwater the removal efficiency was $64 \%$ for $\mathrm{As}(\mathrm{V})$ and $75 \%$ for As(III). Chlorella sp. CB4 provided a viable option for treatment of As laden water.
\end{abstract}

\section{INTRODUCTION}

Interests seemed to rise in applying biological approaches for arsenic removal with plants (terrestrial and aquatic) and a plethora of microorganisms. It offered advantage over other methods being efficient, environmentally sustainable, and socio-economically acceptable. In recent days attempts were made to use microalgae, living cells or dead biomass for removing heavy metals from contaminated water (Kumar and Oommen, 2012; Podder and Majumder, 2015). Microalgae living at the very bottom of the food chain, are widely dwelling in terrestrial and aquatic environments and play an important role in arsenic cycling (Duncan et al., 2015; Wang et al., 2014). They reduce arsenic toxicity by transforming pollutants into non-hazardous materials by certain mechanism like cell surface binding (adsorption), As(III) oxidation, $\mathrm{As}(\mathrm{V})$ reduction, methylation, transformation into arsenosugars or arsenolipids, chelation of As(III) with glutathione and phytochelatins, as well as excretion from cells, etc. (Jiang et al., 2011) Several flocculating microalgae have also been reported, such as Chlorella vulgaris, Ettliatexensis, and Scenedesmus obliquus to remove arsenic from aqueous phase. Present study was attempted to assess the potential of microalgae Chlorella sp. CB4 to remove As(III) and As(V) from aqueous phase in optimized conditions.

\section{EXPERIMENTAL}

Chlorella sp. CB4 (Gene Bank ID No. JQ710683; NCBI databank), a freshwater green microalga was collected from the Bioengineering repository, BIT, Mesra, Jharkhand, India and grown in sterile Tris Acetate buffer (TAP) media. The culture was incubated at $25^{\circ} \mathrm{C}$ under light (8000 lux) with photoperiod of 16:8 h (light: dark). In addition to simple microscopic examination samples were examined under SEM to observe morphological changes in cell structure and/or after adsorption. FTIR in infrared spectra region $4000-500 \mathrm{~cm}^{-1}$ was used to determine the responsible functional group for adsorption.

Batch experiments were performed for arsenic removal from the artificial TAP media to investigate their removal potentiality of $\mathrm{As}(\mathrm{V})$ and $\mathrm{As}(\mathrm{III})$ and optimize initial concentration of $\mathrm{As}(\mathrm{V})$ and $\mathrm{As}(\mathrm{III})$, $\mathrm{pH}$ of the media, temperature and inoculum dose for best removal efficiency. The samples were collected from the culture broth at 3 days interval initially for As(III) but later it was observed that removal for As $(V)$ was a rapid process and hence it was harvested every 8 hours up to 3 days to see maximum removal. The residual As(III) and As(V) concentrations in the culture broth were analyzed in ICP-OES (Perkin Elmer Optima 2100DV). Algal removal of arsenic was finally conducted with two experimental set up in glass tank $(30 \mathrm{~cm} \times 30 \mathrm{~cm} \times 20 \mathrm{~cm}$ dimensions' volume $\left.18000 \mathrm{~cm}^{3}\right) .5 \mathrm{~L}$ of As free groundwater (tubewell) was dosed with $1 \mathrm{mg} \mathrm{L}^{-1}$ of $\mathrm{NaAsO}_{2}$ and $\mathrm{Na}_{3} \mathrm{AsO}_{4}$ for $\mathrm{As}(\mathrm{III})$ and $\mathrm{As}(\mathrm{V})$, respectively. Reaction conditions, optimized in the batch experiments were maintained throughout the removal process. Samples were collected at an interval of $8 \mathrm{~h}$ from As(III) set up (up to $72 \mathrm{~h}$ ) and 3 days from $\mathrm{As}(\mathrm{V})$ set up (up to 24 days).

The metal ion removal efficiency was calculated using equation (1) as follows (Ji et al., 2011).

$\mathrm{E}=\left(\mathrm{C}_{0}-\mathrm{C}_{\mathrm{f}} / \mathrm{C}_{0}\right) \times 100$

where $\mathrm{E}$ represents: removal efficiency of metal ions (\%); $\mathrm{C}_{0}$ and $\mathrm{C}_{f}$ : initial and final concentrations of $\mathrm{As}$ $\left(\mathrm{mg} \mathrm{L}^{-1}\right)$ in the medium respectively. 

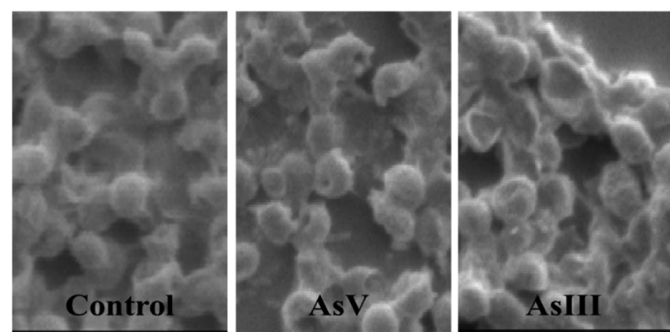

Figure 1. SEM image of microalgae Chlorella sp. CB4 before adsorption (control), after adsorption of $\mathrm{As}(\mathrm{V})$ and As(III).

Table 1. Optimized physical environmental condition.

\begin{tabular}{lll}
\hline & \multicolumn{2}{l}{ Optimized condition } \\
\cline { 2 - 3 } Parameters & $\mathrm{As}(\mathrm{V})$ & $\mathrm{As}(\mathrm{III})$ \\
\hline Initial concentration & $1 \mathrm{mg} \mathrm{L}$ & $1 \mathrm{mg} \mathrm{L}^{-1}$ \\
$\mathrm{pH}$ & $\mathrm{pH}$ & $\mathrm{pH} 7$ \\
Temperature & $25^{\circ} \mathrm{C}$ & $25^{\circ} \mathrm{C}$ \\
Inoculum dose & $1: 50$ & $1: 10$ \\
Final removal & $87 \%$ & $86 \%$ \\
\hline
\end{tabular}

\section{RESULTS AND DISCUSSION}

\subsection{Characterization}

In SEM images, the smooth and homogenous surface of Chlorella sp. CB4 turned out to be rough and heterogeneous on adsorption of As(III) and As(V) (Fig. 1). Presence of As did not affect the density of the nodules, suggesting that the growth of the nodular consortium remains unaffected by the presence of As in the growth medium. The nodules appeared to be glued which might be due to the excessive extra-cellular polysaccharides (EPS) production, a well-known response against stress (Podder and Majumder, 2016).

EDX confirms the adsorption of $\mathrm{As}(\mathrm{III})$ and $\mathrm{As}(\mathrm{V})$ in the surface of the algae. FTIR spectrum of Chlorella sp. CB4 suggested that $\mathrm{C}-\mathrm{H}$ bond of $\mathrm{CH}_{2}$ groups, hydroxyl and carboxyl groups are chiefly responsible for arsenic blinding.

\subsection{Optimization of adsorption parameters}

Removal efficiency achieved for As(V) was $87 \%$ and for As(III) was $86 \%$. The optimized environmental conditions are presented in Table 1.

\subsection{Kinetics study}

The kinetics study confirmed that the current biosorption was best fitted to pseudo-first order kinetic model for both arsenic species (As(III) $\left.-\mathrm{R}^{2}=0.8761\right)$ and $\left(\mathrm{As}(\mathrm{V})-\mathrm{R}^{2}=0.0961\right)$.

\subsection{Glass tank experiment}

In true groundwater, when the removal experiment was conducted with the optimized parameters from the batch experiments, a maximum $\mathrm{As}(\mathrm{V})$ removal of $64 \%$ was obtained on 64th hour of experiment. Similarly, the maximum As(III) removal of $76 \%$ was obtained on 20th day of experiment.

\section{CONCLUSION}

The experimental results of phycoremediation of As by living microalgae Chlorella sp. CB4 from aqueous phase proved the technique to be feasible, which could remove up to $64 \%$ of $\mathrm{As}(\mathrm{V})$ and $75 \%$ of $\mathrm{As}(\mathrm{III})$ from groundwater in optimum conditions. However, for making the water fit for consumption, it has to undergo the removal process twice, so that, the residual concentration of arsenic is within the permissible limit. Further, it can be concluded that, Chlorella sp. CB4 can be a viable option for treatment of As laden water due to their rapid growth rate and good removal capacity.

\section{ACKNOWLEDGEMENTS}

Department of Science and Technology, New Delhi is highly acknowledged for funding the SERB Young Scientist Project SR/FTP/ES-2/2013 for this study.

\section{REFERENCES}

Duncan, E., Maher, W. \& Foster, S. 2015. Contribution of arsenic species in unicellular algae to the cycling of arsenic in marine ecosystems. Environ. Sci. Technol. 49(1): 33-50.

Ji, L., Xie, S., Feng, J., Li, Y. \& Chen, L. 2011. Heavy metal uptake capacities by the common fresh water green alga Cladophora fracta. J. Appl. Phycol. 24(4): 979-983.

Jiang, Y., Purchase, D., Jones, H. \& Garelick, H. 2011. Effects of arsenate $\left(\mathrm{As}^{5+}\right)$ on growth and production of glutathione (GSH) and phytochelatins (PCS) in Chlorella vulgaris. Int. J. Phytoremed. 13(8): 834-844.

Kumar, J.I. \& Oommen, C. 2012. Removal of heavy metals by biosorption using freshwater alga Spirogyra hyalina. J. Environ. Biol. 33(1): 27-31.

Podder, M.S. \& Majumder, C.B. 2015. Phycoremediation of arsenic from wastewaters by Chlorella pyrenoidosa. Groundwater Sust. Develop. 1(1-2): 78-91.

Podder, M.S. \& Majumder, C.B. 2016. Arsenic toxicity to Chlorella pyrenoidosa and its phycoremediation. Acta Ecol. Sin. 36(4): 256-268.

Wang, N.X., Huang, B., Xu, S., Wei, Z.B., Miao, A.J., Ji, R. \& Yang, L.Y. 2014. Effects of nitrogen and phosphorus on arsenite accumulation, oxidation, and toxicity in Chlamydomonas reinhardtii. Aquat. Toxicol. 157: 167-174. 